\title{
Developing and Optimizing Bacteriophage Treatment to Control Enterohemorrhagic Escherichia coli on Fresh Produce
}

\author{
Abigail B. Snyder ${ }^{\mathrm{a}}$, Jennifer J. Perry ${ }^{\mathrm{a}}$, Ahmed E. Yousef ${ }^{\mathrm{a}, \mathrm{b} \#}$ \\ ${ }^{a}$ Department of Food Science \& Technology, \\ ${ }^{b}$ Department of Microbiology, \\ The Ohio State University, Columbus, Ohio 43210, United States
}

Running title: Control of $E$. coli on fresh produce by bacteriophage.

\#Address correspondence to Ahmed E. Yousef (yousef.1@osu.edu), 2015 Fyffe Court, Columbus, $\mathrm{OH} 43210$ 


\section{ABSTRACT}

Bacteriophages are potentially useful in controlling foodborne pathogens on minimally processed products since phage application is a non-destructive treatment. The purpose of this study was to evaluate the efficacy of a newly isolated environmental bacteriophage against enterohemorrhagic Escherichia coli on fresh produce, and optimize the treatment with consideration for potential application. Seven anti E. coli O157:H7 EDL933 bacteriophages were isolated from various sources; the most promising was isolated from municipal wastewater. This isolate (designated as E. coli phage OSY-SP) was propagated with the host, in a growth medium, to a titer of $10^{8} \mathrm{PFU} / \mathrm{ml}$. Before inoculation into fresh produce, E. coli phage OSY-SP was incubated with the host bacterium, spent medium was filter-sterilized, and the resulting crude lysate was used as a source of phage inocula for preliminary experiments. For optimized testing, phage in the crude lysate was purified by ultra-centrifugation and resuspension in phosphatebuffered saline. Efficacy of phage treatments was determined as a function of fresh produce type (cut green pepper or spinach leaves), treatment time ( 2 or 5 minutes rinsing), and temperature of holding treated produce $\left(4^{\circ} \mathrm{C}, 25^{\circ}\right.$, or a combination of both temperatures). Cut green pepper was treated with UV light, to eliminate background microbiota, then spot-inoculated with $E$. coli O157:H7 EDL933 on cut edges, and the inoculum was allowed to dry. Because of its susceptibility to damage, baby spinach leaves were not subjected to a decontamination treatment. These leaves were inoculated with the green fluorescent protein-labeled E. coli O157:H7 B6-914 to facilitate inoculum enumeration in the presence of background microbiota. Phage suspension was applied to the inoculated fresh produce that was subsequently held for three days under variable storage conditions. The optimized phage treatment decreased the populations of pathogenic E. coli by 2.4-3.0 log CFU/g on cut green pepper (5-min rinse) and 3.4-3.5 log CFU/g on spinach leaves (2-min rinse), during $72 \mathrm{~h}$ storage. The majority of this decline was caused by 
25 the antimicrobial action of the phage. These findings suggest the utility of bacteriophage to 26 selectively control pathogens on fresh produce.

27

28 Keywords: Biocontrol, bacteriophage, food safety, enterohemorrhagic Escherichia coli, fresh 29 produce 


\section{INTRODUCTION}

Biocontrol strategies offer a viable alternative to conventional antimicrobial treatments against bacterial pathogens. Processors often rely on preservatives or heat-based interventions to assure the safety of food. Ensuring the safety of fresh produce is inherently challenging; by definition, the product undergoes minimal processing only before consumption. Hence, it was not surprising that one-third of the major foodborne disease outbreaks, occurring in the U.S. between 2003 and 2007, were associated with contaminated fresh produce (Scharff, 2011).

Fresh produce receives minimal treatment between harvest and the time it reaches the consumer. Once harvested, produce is cooled to remove field heat, slowing enzymatic reactions and microbial growth. Maintenance of the cold chain reduces quality changes resulting from enzymatic and microbial activity (Jedermann et al. 2014). Under these conditions, the use of phage to control pathogenic contaminants on fresh produce could be challenging. Phage-mediated lysis is known to depend on host cell proliferation (Drulis-Kawa et al. 2012). reasons.

Following cooling, produce may be subjected to additional processing such as cutting or shredding to become a ready-to-eat product (Kader, 2002). These manipulations increase lesions 
53 and cut-edge surface area that create environments more conducive to pathogen proliferation than intact surfaces. It has been noted that the efficacy of phage treatments is highly dependent on the attributes of the food matrix (Bigwood et al. 2007; Choinska-Pulit et al. 2015; Geer 1988;

56 Hudson et al. 2004).

Fresh produce is often treated with an initial washing step in a dip tank or on a conveyor. This aids in the removal of soil and other debris, as well as reducing microbial load (Kader, 2002). The water used for washing is likely to contain chlorine, or other commercial antimicrobial or surfactant products. The surfactant helps remove solid dirt and debris from the surface of the product while antimicrobial agents prevent cross-contamination (Raiden et al. 2003). However, several European countries have restriction on the use of such sanitizers. For example, Germany, Switzerland, the Netherlands, Denmark, and Belgium prohibit the use of chlorinated wash waters (Uyttendaele et al. 2014). Use of phage is a viable intervention approach that could also be integrated in these fresh produce processes. However, the phage treatment should be adapted to take into account the inactivation mechanism. The "lysis-from-within" mechanism, which occurs following assembly and release of progeny phages from the host, may be limited by the reduced proliferation of bacteria under refrigerated conditions (Maurice et al. 2013). Increasing the phage-bacteria ratio in the washing step may increase bacterial death by lysis-from-without (Goode et al. 2002; Kudva et al. 1999). Using concentrated phage suspensions can improve the treatment's efficacy because the absorption and penetration of the cell envelope by multiple phage particles can be sufficient to cause cell death (Abedon, 2011; Wiggins et al. 1985). intervention strategies, phage treatment is not likely to be effective against pathogens on all 
products, or even on a given product that has undergone physical modifications (e.g., whole vs. cut). Although a phage preparation may be effective as a spray (or wash) on whole iceberg lettuce, it could be much less effective on whole romaine lettuce, because of the botanical differences between these two products. Phage treatment may also be more promising on bagged fresh-cut than it is on whole produce due to the increased accessibility to product surface. While consumers are likely to accept the concept of using natural antimicrobial agents in food, introduction of viruses as natural predators to harmful bacteria may require consumer education (Greer, 2005; Rimal et al. 2001; Wilcock et al. 2004). Additionally, phage treatment optimization is necessary to make this application a viable tool in ensuring food safety. The goals of this study were to isolate and select a phage that effectively inactivates pathogenic Escherichia coli, and optimize the bacteriophage treatment to control the targeted pathogen on different fresh produce.

\section{MATERIALS AND METHODS}

2.1 Bacterial culture. E. coli $\mathrm{O} 157: \mathrm{H} 7$ was used as the target bacterium in this study. Stock culture, stored at $-80^{\circ} \mathrm{C}$, was transferred to Luria Bertani (LB) broth (Becton, Dickinson and Co., Franklin Lakes, NJ) and incubated overnight at $35^{\circ} \mathrm{C}$. The culture was transferred again in LB broth and incubated at $35^{\circ} \mathrm{C}$ for $12 \mathrm{~h}$ with shaking for use in bacteriophage isolation and purification experiments. For green pepper treatments, E. coli O157:H7 EDL933 (Ohio State University, food safety laboratory culture collection) was used as the inoculum, whereas the fluorescently-labeled E. coli O157:H7 B6-914 (J. LeJeune laboratory, The Ohio State University) was used in experiments for baby spinach. E. coli cells were harvested by centrifugation $(10,000$ $\mathrm{x} g, 3 \mathrm{~min}$ ), re-suspended in phosphate-buffered saline (PBS, $\mathrm{pH} 7.0$ ) to contain $\sim 10^{9} \mathrm{CFU} / \mathrm{ml}$ for 
use in food challenge experiments. However, to increase the initial bacterial load on spinach samples, the cell concentration in the suspension was adjusted to $\sim 10^{10} \mathrm{CFU} / \mathrm{ml}$.

2.2 Purification of phage from the environment. Samples ( $10 \mathrm{~g}$ each) of manure from cattle, sheep, and horse farms (The Ohio State University, Columbus, OH) and sewage effluent (Columbus, Ohio) were screened for the presence of phage active against E. coli O157:H7 EDL933 as described previously (Garcia-Aljaro et al. 2008). Manure enrichments were prepared by mixing a sample with $90 \mathrm{ml} \mathrm{LB}$ broth supplemented with $2 \mathrm{mM}$ calcium chloride and incubating the mixture at $\sim 25^{\circ} \mathrm{C}$ for $\sim 1 \mathrm{~h}$ with shaking. Dilutions (1:10) prepared from enriched sewage and manure were centrifuged $(10,000 \times \mathrm{g}, 10 \mathrm{~min})$. The supernatants $(50 \mathrm{ml})$ were sterilized using a $0.22 \mu \mathrm{m}$ pore size syringe-driven filter unit (Millipore, Billerica, MA). Filter-sterilized manure samples were inoculated with the target bacterium and incubated at $35^{\circ} \mathrm{C}$ for $48 \mathrm{~h}$ with shaking. Filtered sewage samples were mixed with equal volumes of $2 \mathrm{X}$ LB broth, supplemented with $2 \mathrm{mM} \mathrm{CaCl}_{2}$, and inoculated with the target bacterium, followed by incubation under the conditions described previously. Enriched samples were again centrifuged and filter-sterilized to prepare the "crude phage filtrate."

2.3 Isolation of phage candidates. The presence of phage was confirmed by spotting $5 \mu 1$ aliquots of the crude phage filtrate onto a lawn of the target bacterium on LB agar supplemented with $\mathrm{CaCl}_{2}$. Following overnight incubation at $35^{\circ} \mathrm{C}$, the presence of zones of inhibition (i.e., plaques) indicated the presence of lytic bacteriophages. The crude phage filtrate was further purified to obtain isolates of a single phage as follows. Serial dilutions of the filtrate were briefly incubated ( $45 \mathrm{~min}$ ) at $\sim 25^{\circ} \mathrm{C}$ with the target bacterium; incubated culture was added to LB soft agar $\left(0.75 \%\right.$ agar w/w) supplemented with $\mathrm{CaCl}_{2}$ and overlaid on a plate of $\mathrm{LB}$ agar. The agar plates were incubated at $35^{\circ} \mathrm{C}$ for $24 \mathrm{~h}$. Isolated plaque forming units (PFU) were marked, and 
121 agar of a single PFU was excised and re-incubated in growth medium with the target host before

122 pour-plating again to obtain isolated plaques. The plaques were excised once more and the

123 process was repeated a second time to achieve isolation of a single candidate phage.

1242.4 Purified phage preparations. "Crude lysate" for the selected phage was prepared by 125 incubation of the excised plaques with the host, E. coli O157:H7 EDL933, in LB broth 126 supplemented with $\mathrm{CaCl}_{2}(2 \mathrm{mM})$ at $35^{\circ} \mathrm{C}$ for $48 \mathrm{~h}$ with shaking. Following incubation, the 127 culture was centrifuged $(10,000 \times \mathrm{g}, 10 \mathrm{~min})$, filter-sterilized and the resulting "crude lysate" was 128 stored at $4^{\circ} \mathrm{C}$ until used in the preliminary studies. For the food challenge experiments, purified 129 phage suspension was prepared from the crude phage lysates by ultracentrifugation $(28,000 \times \mathrm{g}$, $1303 \mathrm{~h}$ ) to sediment the phage particles, followed by resuspension of the pellet in PBS. Phage 131 preparations were titered prior to use (as described later) and were determined to contain $\sim 10^{8}$ $132 \mathrm{PFU} / \mathrm{ml}$.

$133 \quad 2.5$ Phage titration. Phage titration method was adapted from Wommack et al. (2009). Serial 134 dilutions of phage lysate, or purified phage, were prepared and aliquots were incubated with 135 overnight culture of the host bacterium at $\sim 25^{\circ} \mathrm{C}$ for $45 \mathrm{~min}$. The incubated aliquots were added 136 to molten $\mathrm{LB}$ soft agar supplemented with $\mathrm{CaCl}_{2}$ and overlaid on $\mathrm{LB}$ agar plates. These plates 137 were incubated at $35^{\circ} \mathrm{C}$ for $24 \mathrm{~h}$ and the resulting PFU/ml was recorded as the phage titer.

$138 \quad$ 2.6 Target sensitivity to the phage. Bacteriophage candidates were individually incubated with 139 the target bacterium in $\mathrm{LB}$ broth supplemented with $\mathrm{CaCl}_{2}, 0.1 \%$ peptone water (Becton, 140 Dickinson and Co.) with $\mathrm{CaCl}_{2}(2 \mathrm{mM})$, or phosphate-buffered saline (pH 7.0) with $\mathrm{CaCl}_{2}(2$ $141 \mathrm{mM}$ ). Cultures were incubated at $35^{\circ} \mathrm{C}$ for $8 \mathrm{~h}$ with shaking. Samples were taken every hour, 142 diluted as appropriate in $0.1 \%$ peptone water and spread-plated on LB agar. Plates were 143 incubated at $35^{\circ} \mathrm{C}$ for $48 \mathrm{~h}$ and surviving bacteria was enumerated. The phage causing the 
144 greatest inactivation of the target bacterium was selected for further investigation (Watanabe et al. 145 1970).

2.7 Cross-reactivity. In addition to the target bacterium used for phage isolation, activity of phages against closely-related strains was examined. Activity of the phage isolates was first assessed by spotting the crude lysate $\left(10^{7}\right.$ to $\left.10^{8} \mathrm{PFU} / \mathrm{ml}\right)$ on a lawn of the potential host bacteria. E. coli serotypes or strains $(\mathrm{n}=14)$ were transferred from a stock culture (frozen at $-80^{\circ} \mathrm{C}$ ) into LB broth and incubated at $35^{\circ} \mathrm{C}$ for $12 \mathrm{~h}$ with shaking. Phage isolates were spotted on lawns of various $E$. coli serotypes/strains. Observed inhibition of growth, as marked by clearing where the lysate was spotted, was denoted as susceptibility of the bacteria to phage lysis. Each susceptible strain was then used as the host bacterium to determine titer, as previously described. The degree of reactions (lysis) was characterized as described by Peters et al. (2010).

2.8 Genome size estimation. Pulsed field gel electrophoresis (PFGE) was used to estimate the genome sizes for bacteriophage isolates according to published protocols (Gutierrez et al. 2011; Lingohr et al. 2009). Phage-containing plugs were prepared according the given procedure and gels were run using $6 \mathrm{~V} / \mathrm{cm}$ for $15 \mathrm{~h}$ at $14^{\circ} \mathrm{C}$ with incremental pulses of 2.2-54.2 s.

2.9 Imaging. The E. coli phage was imaged using a published procedure (Ackerman, 2009). Briefly, crude phage lysates were purified by ultracentrifugation $(28,000 \times g, 3 \mathrm{~h})$ to sediment the phage particles followed by re-suspension of the pellet in ammonium acetate buffer $(0.5 \mathrm{M})$. Phage preparations were stained using the negative stain ammonium molybdate (Electron Microscopy Sciences, Hatfield, PA). Stained phage was loaded on copper microscopic grids (Electron Microscopy Sciences, Hatfield, PA) and transmission electron microscopy (TEM) was conducted (OSU Medical Center, The Ohio State University, Columbus, OH). The electron 
166 microscope was calibrated using carbon line grating replica (Electron Microscope Sciences, 167 Hatfield, PA).

2.10 Fresh produce. Green bell peppers were obtained from a local grocery store (Columbus, $\mathrm{OH})$ and held at $4{ }^{\circ} \mathrm{C}$ until use. Peppers were cut into slices ( $\sim 2$ in $\mathrm{x} 3$ in) and transferred to Petri dishes. Sliced pepper was treated with UV in a biosafety cabinet for $1 \mathrm{~h}$ on each side of the slices to eliminate background microbiota (Han et al. 2001). The population of background microorganisms on pepper slices was determined using the method described later; the population was $\sim 10^{4} \mathrm{CFU} / \mathrm{g}$ before and $\leq 10 \mathrm{CFU} / \mathrm{g}$ after UV treatment. Pepper slices were then aseptically cut into smaller pieces ( $\sim 1 \mathrm{~g}$ each) immediately prior to inoculation, and 5 pepper pieces were used for each sampling point. Organic baby spinach was obtained from a local grocer (Columbus, $\mathrm{OH}$ ) and stored at $4^{\circ} \mathrm{C}$. Spinach was divided into $50 \mathrm{~g}$ samples and no attempt was made to eliminate background microbiota to avoid product damage.

2.11 Inoculation of fresh produce. Samples of fresh produce were spot-inoculated with $10-\mu l$ aliquots of the 12-h bacterial culture in a biosafety cabinet. Green pepper pieces were inoculated on cut-edge surfaces to facilitate absorption while spinach leaves were spot-inoculated on leaf surfaces with $10 \times 10-\mu \mathrm{l}$ spots per $50 \mathrm{~g}$. Inocula were allowed to dry for $1 \mathrm{~h}$, at ambient temperature, prior to treatment.

2.12 Treatments. The phage-containing crude lysate was used in the preliminary optimization tests. E. coli-contaminated green pepper pieces were dipped in a beaker containing crude lysate $\left(25^{\circ} \mathrm{C}\right)$ with mixing for 2 or 5 min. Control treatment involved dipping E. coli-inoculated green pepper in phage-free LB broth. Treated pepper was stored at $4^{\circ} \mathrm{C}$ or $25^{\circ} \mathrm{C}$, for both the 2 - and 5-min rinse treatments. E. coli-contaminated spinach leaves were treated with crude phage lysate for 2-min with agitation; the 5-min treatment was damaging to the fragile leaves, thus it was not 
used further. Spinach leaves were then incubated at $4^{\circ} \mathrm{C}$ or $25^{\circ} \mathrm{C}$. Control treatment for spinach leaves was prepared as described for the green pepper control.

Optimized conditions were determined based on the preliminary findings. For the final experiments, purified phage in phosphate-buffered saline solution was used to treat the fresh produce, while the control treatment involved dipping in PBS alone. E. coli-contaminated pepper was rinsed in phage suspension ( 0.5 liter) for 5 -min and stored at either $4^{\circ} \mathrm{C}$ for $72 \mathrm{~h}$ or a combination of $25^{\circ} \mathrm{C}$ for $4 \mathrm{~h}$ and $4^{\circ} \mathrm{C}$ for the remainder of the 72 -h incubation time. Inoculated spinach was rinsed for 2-min in the phage suspension (1 liter) and stored under the same conditions used to treat pepper. Surviving E. coli populations were enumerated at 4, 24, 48, and $72 \mathrm{~h}$ following the phage treatment. Phage titer also was determined at each of these time points.

2.13 Recovery of bacteria. Pepper samples were homogenized with peptone water in a stomacher and homogenates were diluted and spread-plated on LB agar (Becton, Dickinson and Co.). All colonies recovered from green pepper pieces were enumerated. Spinach samples were similarly prepared, but were plated on LB agar supplemented with $100 \mu \mathrm{g} / \mathrm{ml}$ each ampicillin and cycloheximide (Sigma-Aldrich, St. Louis, Mo). After incubation, E. coli O157:H7 colonies which produced green fluorescence under UV light were counted. Replica plating indicated no additional growth limitation to target bacteria grown on ampicillin-containing plates. All plates were incubated at $35^{\circ} \mathrm{C}$ for $24 \mathrm{~h}$.

2.14 Recovery of phage. Homogenized produce samples were serially diluted and titered for phage as described previously. Homogenized spinach samples were filter-sterilized using a 0.22 $\mu \mathrm{m}$ pore size syringe-driven filter unit (Millipore, Billerica, MA) before phage titer was determined. 
2112.15 Data analysis. Optimized experiments were run in triplicate for each treatment condition

212 and standard deviations for each time point were calculated. Comparisons between treatments,

213 with or without phage rinse, were made using the Statistical Analysis Software (SAS), General

214 Linear Method (GLM) procedure (SAS9.2, SAS Institute Inc., Carey, NC). Data were analyzed

215 using the model:

216 Log reduction $=\mu+$ phage treatment + incubation temperature + storage time + error

217 where $\mathrm{p}<0.05$ was considered significant. Log reduction $=\log \mathrm{N}_{0} / \mathrm{N} \mathrm{CFU/g}$, where $\mathrm{N}_{0}$ is the 218 initial population and $\mathrm{N}$ is the population at a given sampling time interval.

Statistical analysis revealed that time was not a significant factor (i.e., populations did not representing $E$. coli population reductions resulting from a given treatment. To measure treatment efficacy, reduction in E. coli population (on $\log \mathrm{CFU} / \mathrm{g}$ basis) was calculated as the difference between treated and untreated E. coli populations at the end of $72 \mathrm{~h}$ storage.

\section{RESULTS} samples (soil, wastewater, livestock manure) yielded seven promising phage isolates active 227 against $E$. coli. These active phages were isolated from sewage and manure. Titers of isolated 228 phages ranged from $10^{4}$ to $10^{8} \mathrm{PFU} / \mathrm{ml}$ following 48 - $\mathrm{h}$ incubation with host bacteria. The 229 highest-titer isolate was further assessed for potential use in food safety applications. Selected 230 phage was incubated at $35^{\circ} \mathrm{C}$ with the host bacterium and produced an average titer of $2.5 \times 10^{8}$ $231 \mathrm{PFU} / \mathrm{ml}$; this was designated as E. coli phage OSY-SP. The genome size of this phage was 232 estimated to be $\sim 150 \mathrm{~Kb}$ using pulsed filed gel electrophoresis. Bacteriophage genomes have 233 been found ranging from 15 to $500 \mathrm{~Kb}$ (Gutierrez et al. 2011). Imaging by TEM showed it was a 
234 tailed phage (Table 1) belonging to the family Myoviridae (Choinska-Pulit et al. 2015).

2353.2 Characterization of the selected phage. The antibacterial efficacy of the E. coli phage 236 OSY-SP was evaluated against 14 E. coli strains incubated at $35^{\circ} \mathrm{C}$. Eight E. coli strains showed 237 considerable sensitivity to the phage, and the corresponding phage titer ranged from 6.9 to 8.9 $238 \log$ PFU/ml (Table 1). Sensitivity was observed in both pathogenic and nonpathogenic E. coli 239 strains. Three E. coli strains appeared resistant to infection; whereas three others had limited 240 sensitivity but phage titer against these strains was not successfully measured. Of the seven $E$. 241 coli $\mathrm{O} 157: \mathrm{H} 7$ strains tested, five showed relatively high sensitivity to this phage isolate.

Inhibition and inactivation of $E$. coli by the phage were tested in LB broth, peptone water, and phosphate-buffered saline (Fig. 1). Phage lytic activity increased when the host cells were 244 dividing rapidly, but refrigerated fresh produce is not expected to support rapid bacterial growth. 245 Therefore, a preliminary assessment of the effectiveness of the candidate phage against E. coli in 246 media which limit the host growth is important in selecting an industry-relevant biocontrol agent. 247 Additionally, re-growth of the host over the course of incubation would not be expected in a nutrient-poor medium. Consistent with these assumptions, E. coli in LB broth showed a typical 249 growth curve, whereas growth was suppressed in the presence of the phage (Fig. 1A). Difference 250 in the populations of treated and untreated E. coli was $>4 \log$ within the first three hours of 251 incubation. However, the population of E. coli recovered to its starting levels by the end of the 252 8-h incubation time. When E. coli was suspended in $0.1 \%$ peptone water, instead of LB broth, 253 growth of untreated populations was impacted negatively and considerable inactivation was 254 observed in the phage-treated culture (Fig. 1B). E. coli phages decreased the target population by 255 about $3 \log$ within the first hour of incubation and the difference in populations of untreated and 256 phage-treated cultures was $5.6 \log$ after $8 \mathrm{~h}$ of incubation. When E. coli cells were suspended in 
257 phosphate-buffered saline solution, very little or no growth was observed and presence of phage

258 decreased the population of the bacterium by $3.5 \mathrm{log}$, on average (Fig. 1C).

3.3 Preliminary phage testing on inoculated fresh produce. Cut green pepper and baby

260 spinach leaves represent the fresh-cut and leafy-green categories of fresh produce, respectively.

261 Background microbiota were relatively easy to eliminate by UV treatment of cut green pepper,

262 hence this product was inoculated with a typical enterohemorrhagic strain, E. coli O157:H7 EDL

263933 , and the population was monitored by plating homogenized samples on LB agar medium. On

264 the contrary, it was not feasible to eliminate background microbiota on spinach leaves without

265 damaging the product. Therefore, this fresh produce was used without prior decontamination and

266 was inoculated with the marker-containing strain, E. coli O157:H7 B6-914. The strain expresses

267 green fluorescent protein (GFP) and antibiotic resistance, hence it was possible to enumerate the

268 inoculated strain on spinach leaves using ampicillin and cycloheximide-containing selective agar

269 medium and differentially count the green-fluorescent colonies under UV light. The crude lysate

$270\left(10^{8} \mathrm{PFU} / \mathrm{ml}\right)$ was used in phage treatments in this set of experiments. A short phage application

271 time (2 min) was employed in order to minimize damage to spinach leaves. Population decrease

272 due to mechanical action of rinsing was assessed by use of two controls: (i) products inoculated

273 with E. coli O157:H7 with no further treatment (control-1), and (ii) products inoculated with $E$.

274 coli $\mathrm{O} 157: \mathrm{H} 7$ and rinsed in sterile LB broth (control-2).

It took $4 \mathrm{~h}$ to prepare the fresh produce for testing; this covers the time between product

276 inoculation until placement in storage. Once fresh produce was treated and placed in the correct

277 storage condition, samples were immediately analyzed and this was considered the zero sampling

278 time. Initial differences (at time zero) in E. coli populations between phage treatment and

279 control-1 are due to the combined effects of phage-induced lysis of the target bacterium and the 

292 storage time.

rinsing action of the lysate solution used for washing the fresh produce. However, initial differences between phage treatment and control-2 are due to the phage action only.

Results of the preliminary experiments are summarized here, and average changes in E. coli population during storage are presented in Supplementary Figures S1-S7. An example of these data, for results of a single run, is shown in Fig 2. The initial anti E. coli action of the phage (i.e., at time zero), expressed as average reduction in $\log \mathrm{CFU} / \mathrm{g}$, was 0.9 for cut green pepper and 1.7 for spinach leaves. The cut surfaces on the green pepper pieces may have trapped inoculated $E$. coli cells and made them less accessible to applied phage, hence the lesser population reduction on green pepper than on spinach leaves. After $72 \mathrm{~h}$ of storage at $4^{\circ} \mathrm{C}$, the average difference in $E$. coli population attributed to phage action was $0.9 \log$ for cut green pepper and $2.0 \log$ for spinach leaves. Based on these data, presence of phage maintained a relatively constant difference in E. coli population between phage-treated and LB broth-dipped produce during the

Populations of $E$. coli on produce stored at $4^{\circ} \mathrm{C}$ remained relatively unchanged during storage, but they increased on products stored at $25^{\circ} \mathrm{C}$, regardless of phage treatment. The increase was greater on spinach leaves than on cut pepper. The nutrients in the crude lysate may have supported some of the growth of E. coli observed on the fresh produce held at $25^{\circ} \mathrm{C}$. These treatments, nevertheless, may represent an abuse scenario where heavily-soiled, microbially-contaminated product is held without refrigeration.

The initial reduction in E. coli populations, caused by the rinsing action of the crude lysate, was greater in spinach leaves than in cut pepper; the corresponding average log reductions for these two produce types were 2.7 and 1.0. Therefore, dipping fresh produce in the phage medium was more effective at removing the cells attached to the leaf surface of spinach as opposed to the 
cells which may have been internalized into the tissues of the cut green pepper.

Increasing the rinsing time of cut green pepper in the crude lysate from 2 to $5 \mathrm{~min}$ augmented the population reduction achieved in phage treatment. The 5-min dip reduced E. coli populations initially by 2 to $2.5 \log$, and this reduction differential was sustained during the $72 \mathrm{~h}$ storage at $4{ }^{\circ} \mathrm{C}$ (data not shown). As no noticeable damage was observed on the cut pepper by the 5-min rinse in phage suspension, this treatment was selected for further testing under the optimized studies.

3.4 Optimized phage treatment. Purified phage, suspended in phosphate-buffered saline, was used in these experiments. The same suspension medium was used to rinse the inoculated produce of control-2. Considering the growth of E. coli on produce at $25^{\circ} \mathrm{C}$ (e.g., Fig. 2), it was determined that the storage of phage-treated fresh produce at $4^{\circ} \mathrm{C}$ would be the most appropriate for optimization studies. However, a distinct advantage was observed in the first $24 \mathrm{~h}$ of storage at $25^{\circ} \mathrm{C}$; i.e., considerable differences between E. coli populations on phage-treated and untreated produce were apparent. Therefore, the optimization experiments included a new storage condition, in which an initial holding period for $4 \mathrm{~h}$ at $25^{\circ} \mathrm{C}$ preceded the transfer of produce to the $4^{\circ} \mathrm{C}$ refrigeration, where it was held for the remainder of the $72 \mathrm{~h}$ storage. It was hypothesized that the initial storage at $25^{\circ} \mathrm{C}$ for $4 \mathrm{~h}$ is sufficient to increase phage titer through replication in the host without increasing the population of the pathogen. Considering the potential pathogen internalization through cut surfaces on green pepper pieces, a 5-min rinse in phage suspension was selected over a 2-min rinse. Baby spinach has delicate leaves that were adversely affected by the 5-min rinse; therefore, the 2-min rinse was selected for this phase of the study.

An example of the optimized study results, for one treatment condition, is shown in Fig. 3, 
326 but pooled data are shown in Fig. 4. For all treatment conditions, incubation time was not found 327 to be significant ( $p>0.05$ ), i.e., populations did not significantly change over the course of the $32872 \mathrm{~h}$ period. Therefore, population reductions for each treatment are reported as a single value, 329 the difference between the treated and untreated population levels at the end of $72 \mathrm{~h}$ storage (Fig. $3304)$.

Phage treatment of contaminated baby spinach leaves reduced E. coli populations by 3.4-3.5

$332 \log$ under either storage condition (Fig. 4). Rinsing alone (i.e., without phage) caused $1.4 \log$ 333 reduction, while the additional $2 \log$ reduction can be attributed to the antibacterial activity of the 334 phage treatment. Phage treatment reduced the population of E. coli on cut green pepper, stored at $3354^{\circ} \mathrm{C}$, by $2.4 \log$ (Fig. 4). The reduction in E. coli population on cut green pepper stored at $33625^{\circ} \mathrm{C} / 4^{\circ} \mathrm{C}$ for $72 \mathrm{~h}$ increased modestly to $3.0 \mathrm{log}$. Rinsing with phage-free medium decreased $E$.

337 coli populations on cut green pepper by $0.8 \mathrm{log}$; thus presence of phage resulted in 1.6-2.2 log 338 reduction. Holding produce at the $25^{\circ} \mathrm{C} / 4^{\circ} \mathrm{C}$ storage condition, compared to $4^{\circ} \mathrm{C}$, did not seem to 339 improve the phage action considerably.

340 Phage titers on produce during storage were measured in triplicate. These trials showed the 341 general trend of an initial increase followed by a decline throughout the storage period (Fig. 5).

342 However, large variability among trials made differences in phage titers during produce storage 343 statistically insignificant $(p>0.05)$. Additionally, phage titers on produce held initially at $25^{\circ} \mathrm{C}$ 344 for $4 \mathrm{~h}$ and that held at $4{ }^{\circ} \mathrm{C}$ for the whole storage period were not statistically significant $(p>$ $3450.05)$ at all sampling points.

\section{4. DISCUSSION}

Phage candidates active against enteric pathogens were readily isolated from 348 environmental samples, and preliminary selections were made based on titer levels. Generally, a 
higher titer is preferable since it indicates more replication of the phage or larger burst size and, as a consequence, more phage particles produced to perpetuate its lytic cycle. It may also indicate a high affinity of the phage for the target receptor displayed by the host. The concentration of phages in the crude lysate is dependent on many factors, but higher titer values suggest the sensitivity of the target to phage infection (Wiggins et al. 1985).

Titer is only one of the criteria for predicting phage efficacy in pathogen control. A limitation of using titer as a proxy for activity was illustrated by the results of the cross reactivity analysis (Table 1). Although 11 of 14 E. coli strains tested showed sensitivity to the candidate phage when the lysate was spotted on a lawn of target bacteria, three of these strains failed to produce successful phage titer because the resulting plaques were too faint to enumerate. Cross reactivity results also suggested that it would be desirable that food processors use a cocktail of phages active against a broader spectrum of pathogenic E. coli strains. A cocktail of phages not only increases the activity spectrum for the treatment (Leverentz et al. 2001), it also decreases the probability of resistance mutations developing within the target population (Hudson et al. 2004; O'Flynn et al. 2004; Stern and Sorek 2011).

Research on a single phage isolate is required for characterization of its potential efficacy. Previous findings have demonstrated that the use of a single phage can reduce target bacterium populations by approximately 1.0 to $2.0 \log$ (Hudson et al. 2004; Sharma 2013). The E. coli phage isolated from sewage effluent was selected based on titer level, cross reactivity spectrum, and inhibition of target's growth in liquid culture. The selected phage was able to reduce pathogenic $E$. coli in a medium that supported its growth, as well as in media which were less conducive to bacterial growth (Fig. 1). This suggested that the selected E. coli phage would be successful in reducing target populations in a relatively unfavorable environment. Bigwood et al. 
372 (2008) have shown that high phage-bacterial ratio is more effective in reducing both high and

373 low levels of target pathogen. In the challenge studies described here, high levels of E. coli were

374 applied to inoculated produce. However, in many instances of natural contamination, pathogens

375 are present at relatively low levels in food (Bhagwat, 2003). This may prove challenging to

376 commercialization as Kasman et al. (2002) found that in systems with low levels of bacterial

377 targets, additional barriers to efficacy exist and, subsequently, that cell concentration and

378 absorption time should be considered in determining a sufficient concentration of phage to apply

379 in biocontrol strategies.

Preliminary results suggested that the combination of incubation conditions (initially at $25^{\circ} \mathrm{C}$, followed by refrigeration at $4^{\circ} \mathrm{C}$ ) for phage-treated produce would allow for growth of the 382 target bacterium, which would facilitate the lytic activity of the phage while preventing later 383 outgrowth of the host and other plant associated biota. However, optimized studies did not 384 support this hypothesis (Fig. 4). No significant difference was observed between produce stored 385 solely under refrigeration conditions compared to produce that was initially incubated at $25^{\circ} \mathrm{C}$ for $3864 \mathrm{~h}$. The discrepancy between the preliminary and optimized experimental findings may be 387 explained by the differences in treatment and produce inoculation methods. Preliminary tests 388 included an LB broth rinse as a control. Additionally, E. coli inocula were suspended in LB broth.

389 This is in contrast to optimized studies where rinse treatments were done in PBS and bacterial 390 inoculum was similarly suspended in PBS. The presence of residual media on the produce may 391 have facilitated outgrowth of the host to a greater extent than what could be attributed to 392 incubation conditions alone (Kocharunchitt et al. 2008). 
investigations (e.g., Wiggins et al. 1985). The reduction in bacterial population may be due in part to lysis-from-without. Alternatively, bacteria may initially still be replicating new phage, even if the bacterial replication rate does not result in considerable population growth. On the contrary, cell death may result once phage-infected bacteria are plated onto growth media at which point replication is initiated and lysis-from-within occurs. Because of the lower 400 attachment rate of some phages, including T4-like E. coli phages, it is impractical to rely only on 401 lysis-from-within for the control of mesophillic pathogens in products which are stored in 402 refrigerated conditions to preserve their quality (Hudson et al. 2004). Additional work is required 403 to assess efficacy under conditions of lower bacterial host concentrations often present in natural 404 contamination (Hagens and Loessner 2010; Kasman et al. 2002).

405 Comparing phage efficacy between the two produce types is difficult due to the difference in 406 inoculation method and bacterial strains utilized. E. coli O157:H7 EDL933 was used to inoculate

407 green pepper pieces following a decontamination step which reduced the aerobic mesophilic 408 counts on the surface of the green pepper below the detection limit (10 CFU/g). The surface of 409 baby spinach leaves was not decontaminated because of its inherent texture and fragility, so a 410 fluorescently-labeled E. coli O157:H7 was used to enumerate the surviving population. Although 411 efficacy of the phage was strongly affected by produce type $(\mathrm{p}<0.0001)$, for which the 412 difference in strain was likely not solely responsible. This difference may also be explained by 413 the inoculation methods for the two experiments. Green pepper pieces were spot-inoculated on 414 cut surfaces and inoculum clearly diffused into the tissue of the pepper. Conversely, spinach 415 leaves were spot-inoculated on undamaged surfaces and the inoculum was dried as a film on the 416 leaf surface. Additionally, spinach leaves also harbored normal levels of commensal biota, which 417 may impact not only the attachment and growth of the inoculated pathogen, but also compete 
418 with the targeted bacteria as alternative phage receptors.

419 In conclusion, phage treatment was successful at significantly reducing target populations in

420 in the tested fresh produce. The addition of phage to the rinse buffer accomplished an additional

421 population reduction of up to $2 \log$, compared to rinsing alone. Given that a rinse step is already

422 in place for industrial processing of produce, no modification to infrastructure or processing

423 environment would be expected to allow implementation of the phage treatment proposed here,

424 but identification of specific challenges would require larger scale experimentation and

425 involvement of industry partners. Currently, members of this research team are investigating the

426 potential for a phage rinse in combination with other hurdle technologies.

\section{Acknowledgments}

428 Financial support was provided in part by U.S. Department of Agriculture, National Institute of 429 Food and Agriculture, grant 2009-51110-05902, and in part by the Ohio Agricultural Research 430 and Development Center, College of Food, Agricultural and Environmental Sciences, The Ohio 431 State University. 


\section{References}

Abedon, S.T., 2011. Lysis from without. Bacteriophage 1, 46-49.

Abedon, S. T., Kuhl, S. J., Blasdel, B. G., Kutter, E. M., 2011. Phage treatment of human infections. Bacteriophage 1, 66-85.

Ackerman, H. W., 2009. Basic phage electron microscopy. In: Clokie, M. R. J., Kropinski, A. M. (Eds.), Bacteriophages Methods and Protocols, Volume 1: Isolation, Characterization, and Interactions. Human Press, New York, NY, pp. 113-126.

Bhagwat, A. A., 2003. Simultaneous detection of Escherichia coli O157:H7, Listeria monocytogenes, and Salmonella strains by real-time PCR. Int. J. Food Microbiol. 84, 217-224.

Bigwood, T., Hudson, J. A., Billington, C., 2007. Influence of host and bacteriophage concentrations on the inactivation of food-borne pathogenic bacteria by two phages. FEMS Microbiol. Lett. 291, 59-64.

Bigwood, T., Hudson, J. A., Bigllington, C., Carey-Smith, G. V., Heinemann, J. A., 2008. Phage inactivation of foodborne pathogens on cooked and raw meat. Food Microbiol. 25, 400-406.

Choinska-Pulit, A., Mitula, P., Sliwka, P., Laba, W., Skaradzinska, A., 2015. Bacteriophage encapsulation: Trends and potential applications. Trends Food Sci. Technol. 45, 212-221.

Drulis-Kawa, Z., Majkowska-Skrobek, G., Maciejewska, B., Delattre, A. S., Lavigne, R., 2012. Learning from bacteriophages - Advantages and limitations of phage and phage-encoded protein applications. Curr. Protein Pept. Sci. 13, 699-722.

Garcia, P., Madera, C., Martinez, B., Rodriguez, A., 2006. Bicontrol of Staphylococcus aureus in curd manufacturing processes using bacteriophages. Int. Dairy J. 17, 1232-1239.

Garcia-Aljaro, C., Muniesa, M., Jofre, J., Blanch, A.R. 2008. Genotypic and phenotypic diversity among induced $s t x_{2}$-carrying bacteriophages from environmental Escherichia coli strains. Appl. Environ. Microbiol. 75, 329-336.

Goode, D., Allen, V. M., Barrow, P. A., 2002. reduction of experimental Salmonella and Campylobacter contamination of chicken skin by application of lytic bacteriophages. Appl. Environ. Microbiol. 69, 5032-5036.

Greer, G. G., 1988. Effects of phage concentration, bacterial density, and temperature on phage control of beef spoilage. J. Food Sci. 53, 1226-1227.

Greer, G. G., 2005. Bacteriophage control of foodborne bacteria. J. Food Prot. 68, 1102-1111. 
Gutierrez, D., Martın-Platero, A. M., Rodrıguez, A., Martınez-Bueno, M., Garcıa, P., Martınez, B., 2011. Typing of bacteriophages by randomly amplified polymorphic DNA (RAPD)-PCR to assess genetic diversity. FEMS Microbiol. Lett. 322, 90-97.

Hagens, S., Loessner, M. J. 2010. Bacteriophages for biocontrol of foodborne pathogens: Calculations and considerations. Curr. Pharm. Biotechnol. 11, 58-68.

Han, Y., Linton, R. H., Neilsen, S. S., Nelson, P. E., 2001. Reduction of Listeria monocytogenes on green peppers (Capsicum annuum L.) by gaseous and aqueous chlorine dioxide and water washing and its growth at $7^{\circ} \mathrm{C}$. J. Food Prot. 64, 1730-1738.

Hudson, J. A., Billington, C., Carey-Smith, G., Greening, G., 2004. Bacteriophages as biocontrol agents in food. J. Food Prot. 68, 426-437.

Jedermann, R., Potsch, T., Lloyd, C., 2014. Communicating techniques and challenges for wireless food quality monitoring. Philosophical Transactions A http://rsta.royalsocietypublishing.org/content/roypta/372/2017/20130304.full.pdf

Kader, A. A., 2002. Postharvest technology of horticultural crops. In: Kader, A. A. (Ed.) University of California Agricultural and Natural Resource Publications 3311, Oakland, CA. pp. $39-47$.

Kasman, L. M., Kasman, A., Westwater, C., Dolan, J., Schmidt, M. G., Norris, J. S. 2002. Overcoming the phage replication threshold: a mathematical model with implications for phage therapy. J. Virol. 76, 5557-5564.

Kocharunchitt, C., Ross, T., McNeil, D. L., 2008. Use of bacteriophages as biocontrol agents to control Salmonella associated with seed sprouts. Int. J. Food Microbiol. 128, 453-459.

Kudva, I. T., Jelacic, S., Tarr, P. I., Youderian, P., Hovde, C. J., 1999. Biocontrol of Escherichia coli $\mathrm{O} 157$ with O157-specific bacteriophages. Appl. Environ. Microbiol. 65, 3767-3773.

Leverentz, B., Conway, W. S., Alavidze, Z., Janisiewicz, W. J., Fuchs, Y., Camp, M. J., Chighladze, E., Sulakvelidze, A., 2001. Examination of bacteriophages as a biocontrol method for Salmonella on fresh-cut fruit: A model study. J. Food Prot. 64, 1116-1121.

Lingohr, E., Frost, S., Johnson, R. P., 2009. Determination of bacteriophage genome size by pulsed-field gel electrophoresis. In: Clokie, M. R. J., Kropinski, A. M. (Eds.), Bacteriophages, Methods and Protocols. Volume 2: Molecular and Applied Aspects. Human Press. Hartforshire, UK. pp. 19-26.

Maurice, C. F., Bouvier, C., de Wit, R., Bouvier, T., 2013. Linking the lytic and lysogenic bacteriophage cycles to environmental conditions, host physiology, and their variability in coastal lagoons. Appl. Environ. Microbiol. 15, 2463-2475. 
O’Flynn, G., Ross, R. P., Fitzgerald, G. F., Coffey, A., 2004. Evaluation of a cocktail of three bacteriophages for biocontrol of Escherichia coli O157:H7. Appl. Environ. Microbiol. 70, 3417-3424.

Peters, T., Hopkins, K. L., Lane, C., Nair, S., Wain, J., de Pinna, E., 2010. Emergence and characterization of Salmonella enterica serovar Typhimurium phage type DT191a. J. Clinic. Microbiol. 48, 3375-3377.

Raiden, R. M., Sumner, S. S., Eifert, J. D., Pierson, M. D., 2003. Efficacy of detergents in removing Salmonella and Shigella spp. from the surface of fresh produce. J. Food Prot. 66, 2210-2215.

Reanney, D. C., Marsh, S. C. N., 1972. The Ecology of viruses attacking Bacillus Stearothermophilus in soil. Soil Biol. Biochem. 5, 399-408.

Rimal, A., Fletcher, S. M., McWatters, K. H., Misra, S. K., Deodhar, S., 2001. Perception of food safety and changes in food consumption habits: A consumer analysis. Int. J. Consum. Stud. $35,43-52$.

Scharff, R., 2011. Health-related costs of foodborne illness in the United States. Produce Safety Project, an Initiative of the Pew Charitable Trusts at Georgetown University. http://www.producesafetyproject.org/media.

Sharma, M. 2013. Lytic bacteriophages. Bacteriophage 3, e25518.

Stern, A., Sorek, R., 2011. The phage-host arms-race: Shaping the evolution of microbes. BioEssays 33, 43-51.

Uyttendaele, M., Jacxsens, L., Boxstael, S.V., 2014. In: Hoorfar, J. J. (Ed.), Issues surrounding the European fresh produce trade: a global perspective. Global Safety of Fresh Produce: A Handbook of best practice, innovative commercial solutions and case studies. Woodhead Publishing, Philadelphia, PA, pp. 33-51.

Watanabe, K., Takesue, S., Jin-Nai, K., Yoshikawa, T., 1970. Bacteriophage active against the lactic acid beverage-producing bacterium Lactobacillus casei. Appl. Environ. Microbiol. 20, 409-415.

Wiggins, B. A., Alexander, M., 1985. Minimum bacterial density for bacteriophage replication: Implications for significance of bacteriophages in natural ecosystems. Appl. Environ. Microbiol. $49,19-23$.

Wilcock, A., Pun, M., Khanona, J., Aung, M., 2004. Consumer attitudes, knowledge and behavior: a review of food safety issues. Trends Food Sci. Technol. 15, 56-66.

Wommack, K. E., Williamson, K. E., Helton, R. R., Bench, S. R., Winget, D. M. 2009. Methods for isolation of viruses from environmental samples. In: Clokie, M. R. J., Kropinski, A. M. (Eds.), 
Bacteriophages Methods and Protocols, Volume 1: Isolation, Characterization, and Interactions. Human Press, New York, NY, pp. 3-14. 
Table 1. Anti- Escherichia coli spectrum and transmission electron microscope imaging of the newly-isolated bacteriophage

\begin{tabular}{|l|l|l|}
\hline Serotype/Strain & Titer $^{\mathbf{a}}$ & Inhibition \\
& & \\
\hline 054220 & 6.9 & +++ \\
\hline 455 & 7.0 & +++ \\
\hline ATCC 25922 & - & - \\
\hline B8508 & Not measurable & ++ \\
\hline K12 & 8.3 & ++ \\
\hline O157:H1 & Not measurable & S \\
\hline O157:H7 32A & - & - \\
\hline O157:H7 32C & 8.0 & +++ \\
\hline O157:H7 32DB & 8.8 & +++ \\
\hline O157:H7 EC88 & 8.5 & +++ \\
\hline $\begin{array}{l}\text { O157:H7 } \\
\text { EDL933 }\end{array}$ & 8.4 & +++ \\
\hline $\begin{array}{l}\text { O157:H7 GFP } \\
\text { labeled }\end{array}$ & 8.9 & +++ \\
\hline 157:H7 WT & - & - \\
\hline O157:H12 & Not measurable & + \\
\hline
\end{tabular}

${ }^{\text {a }}$ Titer values, recorded as $\log (\mathrm{PFU} / \mathrm{ml})$, for the phage isolate when the corresponding serotype/strain was used as a host; results are averages of triplicate assays. The designation "not measurable" indicates that the plaques were not defined enough for enumeration.

${ }^{b}$ Inhibition values recorded as: +++ , confluent lysis; ++, semi-confluent lysis; +, individual plaques; $\mathrm{S}$, shadow lysis; -, no lysis. 
Figure 1: Changes in Escherichia coli populations in the presence of bacteriophage in different media. (A) LB broth; (B) peptone; (C) phosphate-buffered saline. Symbols: Untreated ( $\mathbf{\Delta}$ ); Phage-treated $(\bullet)$.

Figure 2: Changes in Escherichia coli B6-914 population on baby spinach leaves after a 2-min rinse in crude lysate and incubation for 72 hours at $25^{\circ} \mathrm{C}$ (an example of preliminary data). Initial E. coli population before the application of any treatment (i.e., time zero) for all treatments was 6.6 Log CFU/g. Symbols: Untreated (๘); Rinse with medium only ( $\bullet$; Rinse with phage-containing crude extract $(\bullet)$.

Figure 3: Initial reduction in Escherichia coli O157:H7 B6-914 population on baby spinach leaves after washing in a purified phage suspension, and subsequent changes in population during storage of inoculated product at $25^{\circ} \mathrm{C}$ for 4 hours, followed by storage at $4{ }^{\circ} \mathrm{C}$ for the remaining 68 hours. Initial E. coli population for all spinach treatments was 5.6 Log CFU/g. Zero time represents the commencement of storage for treated produce. Symbols: Control 1: Untreated $(\bullet)$; Control 2: Rinse with medium only $(\bullet)$; Treatment: Rinse with phage suspension $(\bullet)$.

Figure 4: Reduction in populations of Escherichia coli $\mathrm{O} 157: \mathrm{H} 7\left(\log \mathrm{N}_{0} / \mathrm{N}\right.$ CFU/g) on fresh produce caused by phage treatment and incubation at $4{ }^{\circ} \mathrm{C}$ for $72 \mathrm{~h}$, or at $25^{\circ} \mathrm{C}$ for $4 \mathrm{~h}$ followed by $4^{\circ} \mathrm{C}$ for $68 \mathrm{~h} . \mathrm{N}_{0}$ is the initial population and $\mathrm{N}$ is the population after $72 \mathrm{~h}$ storage. *Indicates significant difference $\mathrm{P}<0.001$

Figure 5: Escherichia coli phage titer (Log PFU/g) on baby spinach leaves (Panel A) following a 2-min rinse, and on green pepper pieces (Panel B) following a 5-min rinse in purified phage suspension and holding the product at $4{ }^{\circ} \mathrm{C}$ for $72 \mathrm{~h}$ (solid lines) or at $25^{\circ} \mathrm{C}$ for 4 hours, then $4^{\circ} \mathrm{C}$ for 68 hours (dashed lines). 
Fig. 1

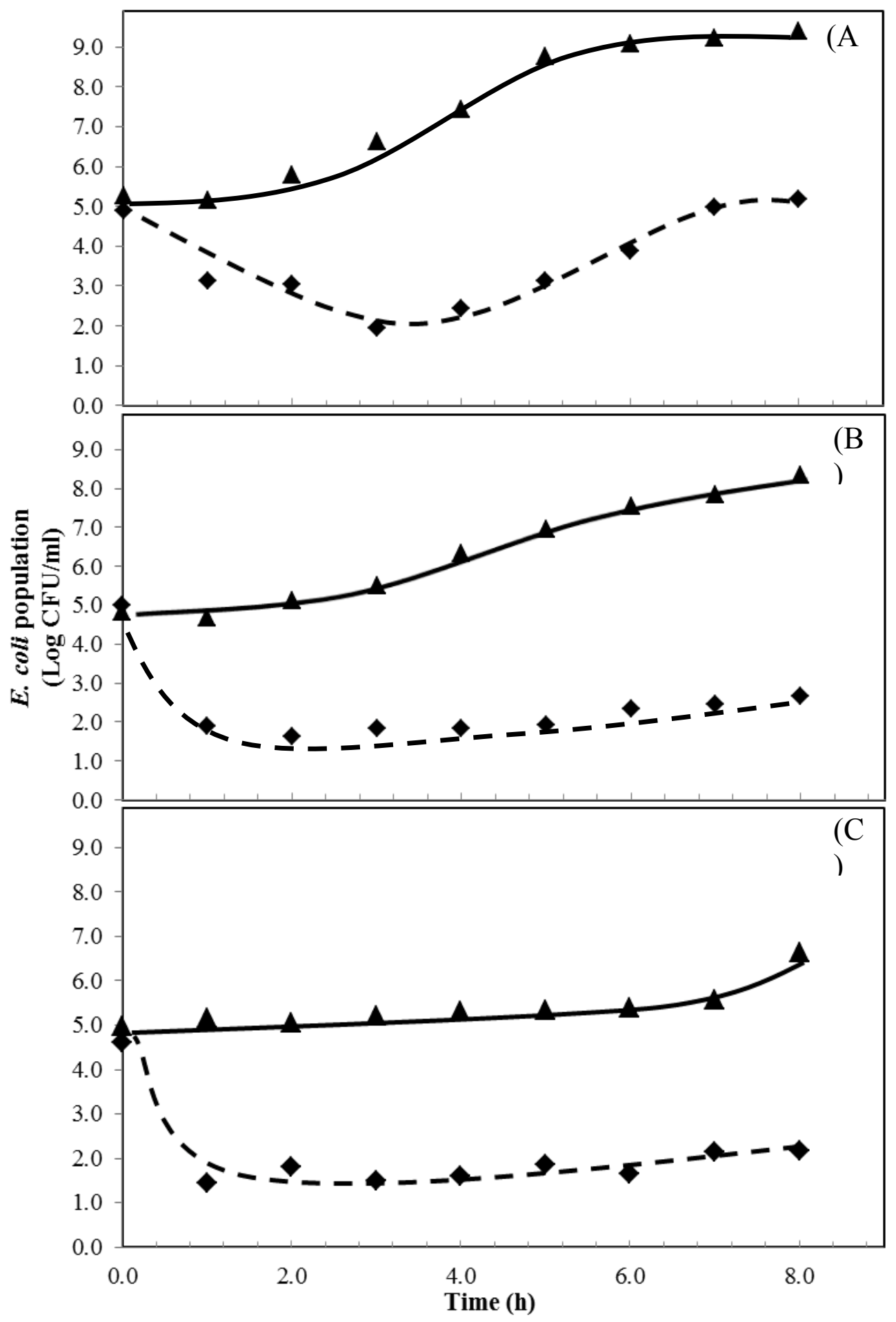


Fig. 2

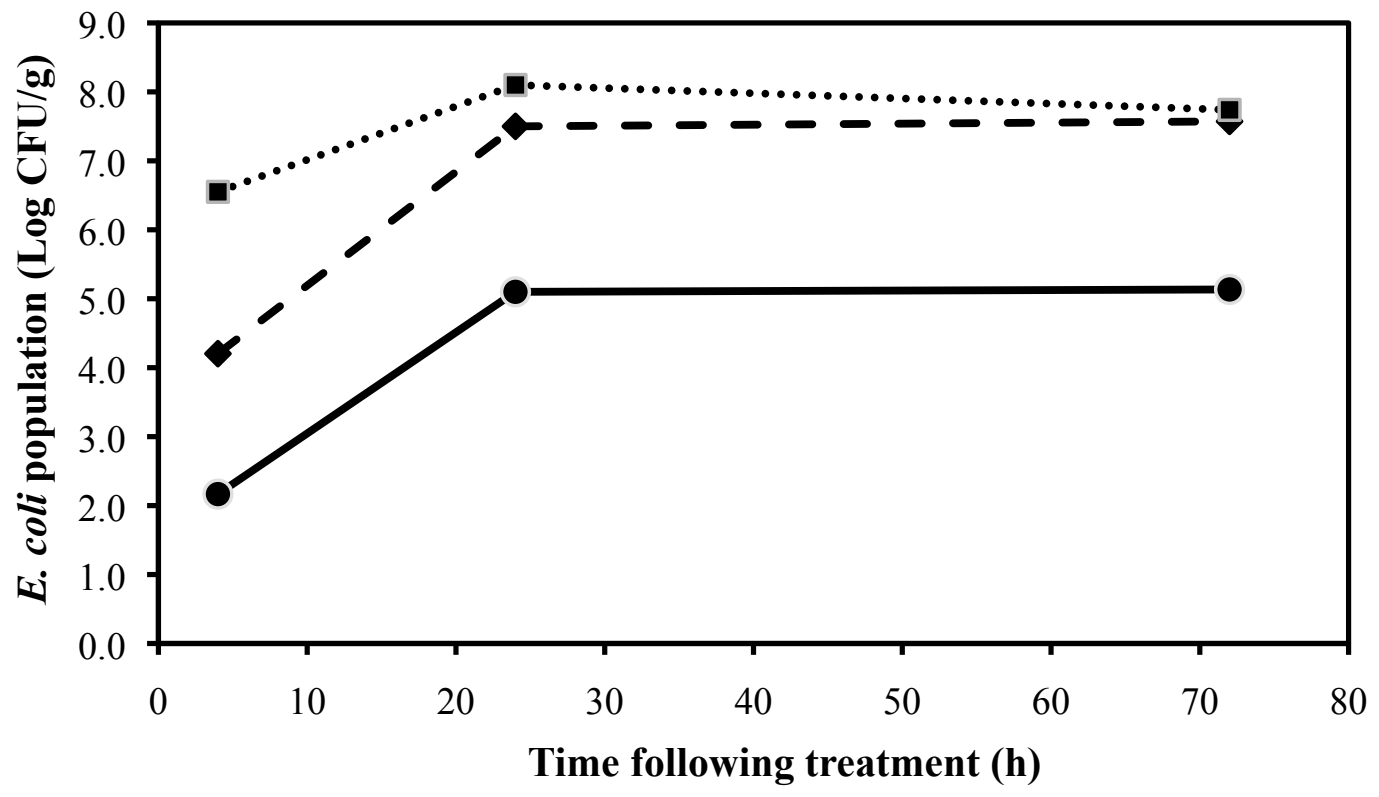


Fig. 3

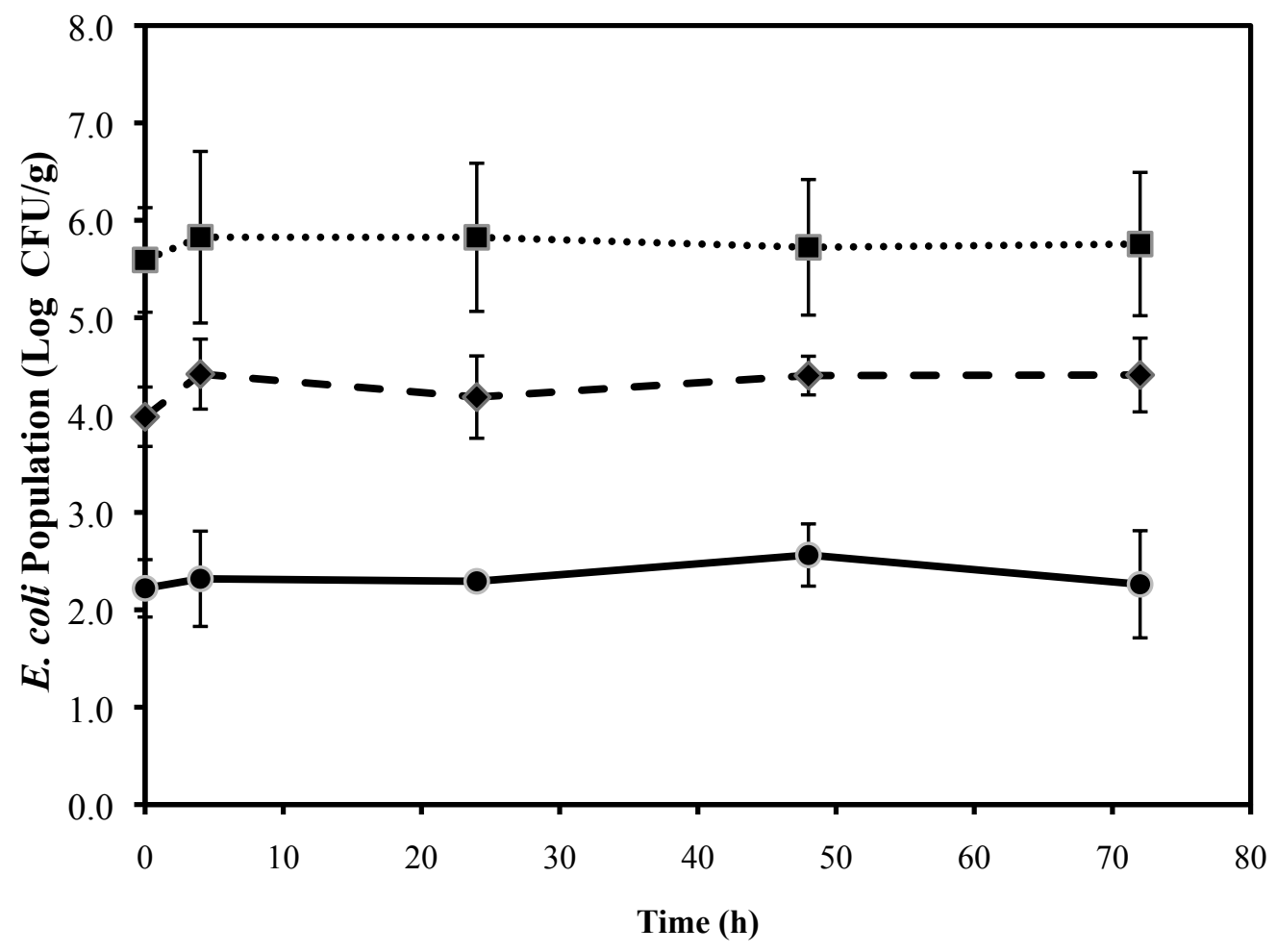


Fig. 4

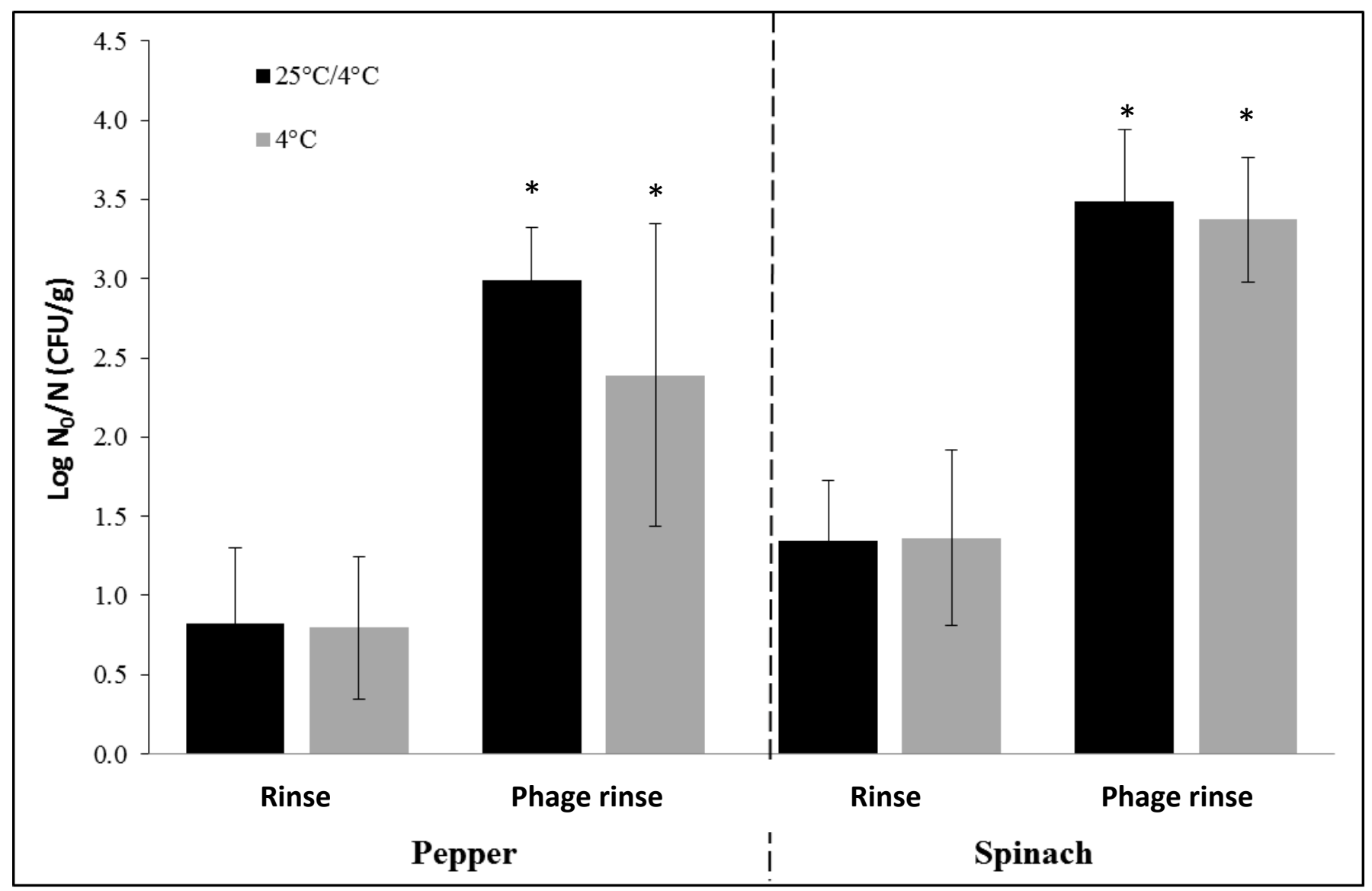


Fig. 5
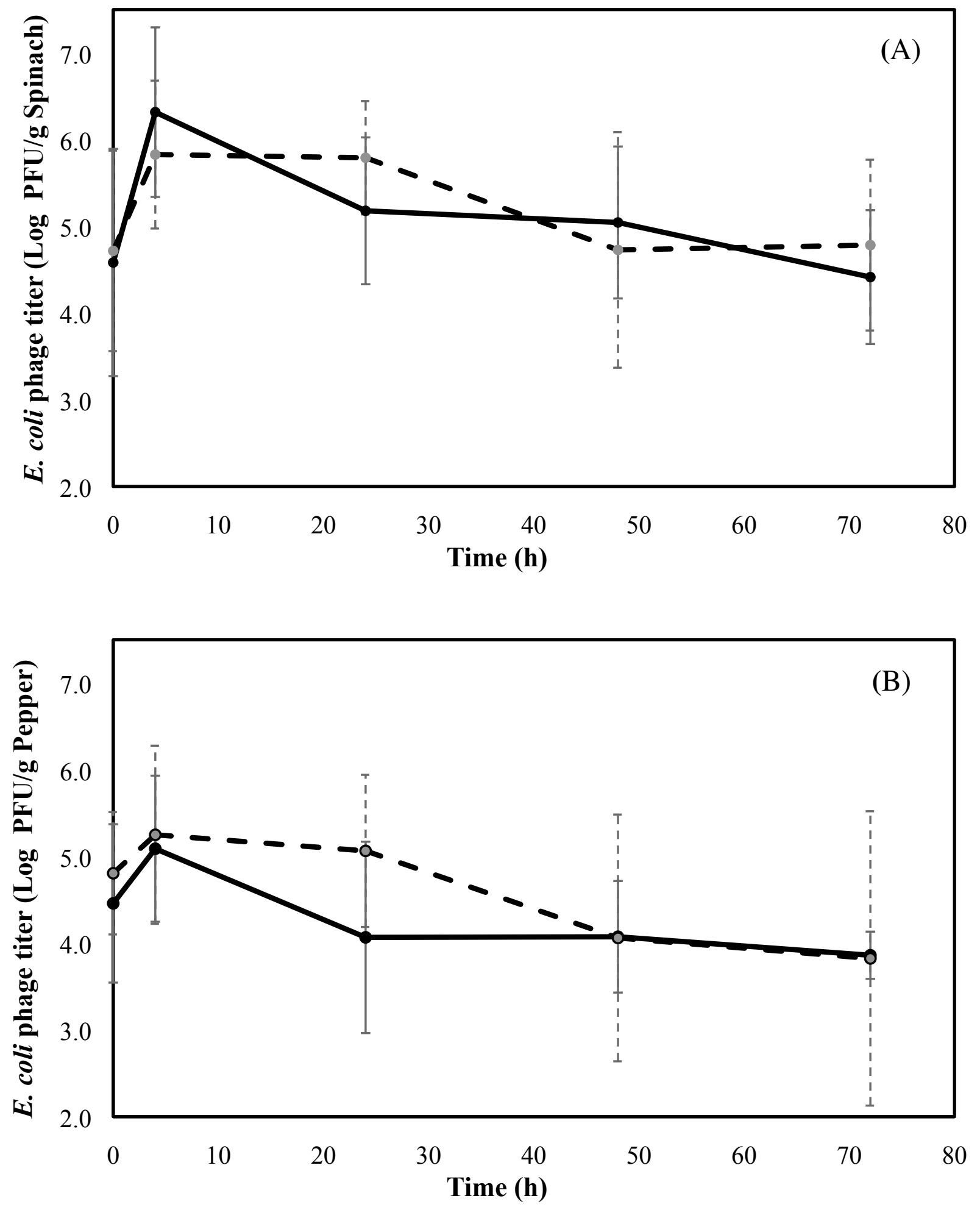